\title{
Circuit
}

Musiques contemporaines

\section{« Moi » : un autoportrait par José Evangelista}

\section{José Evangelista}

Volume 27, numéro 3, 2017

Illusions polyphoniques : José Evangelista et l’hétérophonie

URI : https://id.erudit.org/iderudit/1042840ar

DOI : https://doi.org/10.7202/1042840ar

Aller au sommaire du numéro

Éditeur(s)

Circuit, musiques contemporaines

ISSN

1183-1693 (imprimé)

1488-9692 (numérique)

Découvrir la revue

Citer ce document

Evangelista, J. (2017). « Moi » : un autoportrait par José Evangelista. Circuit, 27(3), 63-65. https://doi.org/10.7202/1042840ar d'utilisation que vous pouvez consulter en ligne.

https://apropos.erudit.org/fr/usagers/politique-dutilisation/ 


\section{«Moi » : un autoportrait par José Evangelista}

"Moi' ${ }^{1}$

José Evangelista

Valence (Espagne), 5 août 1943; établi au Canada depuis 1969.

Études d'harmonie et composition avec Vicente Asencio (1960-1965).

Licence ès sciences physiques. Travaux en informatique (1967-1970).

Études de composition avec André Prévost (1970-1973) et Bruce Mather (1977-1981).

Enseignement à l'Université de Montréal (1974-2008). Professeur émérite.

\section{Axes de création}

- Musique immobile (1975-1980):

Coros tejiendo voces alternando, Immobilis in mobili, Carrousel, Motionless Move

- Cultures du monde, gamelan (1980-1999):

Motionless Move, Clos de vie, Monody Quartet (II et III), Labyrinthe, Ô Bali, Ô Java, Concerto Kebyar, Bali Symphony, Ô Gamelan

- Mélodies traditionnelles d'Espagne (depuis 1988):

Monodías españolas, Ramillete de canciones populares, Airs d'Espagne, Spanish Garland, Nuevas monodías españolas, Cancionero, Cantares

- Autres cultures:

O Niugini, Alap E Gat, Manuscrit trouvé à Saragosse, Viola Song

- Musique vocale:

- Chœur et ensemble vocal: Coros tejiendo voces alternando, Cantus sacri, Noche oscura, Les animaux de personne, Songs of Innocence and of Experience, Leçons du Tao
1. Ce document schématique nous a été fourni par José Evangelista, le 23 mars 2017, dans un courriel intitulé "Moi". Pour paraphraser le sculpteur Arman, il s'agit d'un "autoportraitrobot". Le compositeur s'y réfère constamment lorsqu'il est appelé à donner des conférences ou des interviews [ndlr]. 
- Monodrames (1974-2008): Plume, La porte, Alice E Friends, Bukowski Stories, Exercices de style

- Opéras: Exercices de conversation (1991/1999), Manuscrit trouvé à Saragosse (1997-2001)

- Tendances néoclassiques:

Concerto con brio, Concerto des saisons, Symphonie minute, Violinissimo, Hautbois concertant

\section{Techniques}

- Nouvelle mélodie comme cantus firmus (depuis 1980), pseudo-modalité: Motionless Move, Vision, Clos de vie, Ô Bali, Alap G Gat, etc.

- Hétérophonie monodique (depuis 1982):

- Chambre: Vision, Ô Bali, Duo staccato, Merapi

- Solo: Monodías españolas (piano), Ecos (orgue), Labyrinthe (harpe), Nuevas monodías españolas (piano), Bis (piano), Sonate (orgue, en cours de composition)

- Orchestre: Piano concertant, Violinissimo, Ô Java, Cancionero, Viola Song, Cant

- Chœur: Cantus sacri, Noche oscura, Songs of Innocence and of Experience

- Harmonisation d'une mélodie par elle même :

Motionless Move (registres fixes), Alap E Gat, Viola Song, Accelerando

- Ostinato harmonique :

Concertino, Concerto des saisons

- Harmonie par quintes:

La porte, Symphonie minute, etc.

\section{Extraits musicaux}

- Motionless Move

Musique immobile. Gamelan, CF [cantus firmus] cyclique en registres fixes et canon. Structure colotomique. Stratification. Mimétisme cordes, percussion et bois. Mimétisme avec des sons électroniques.

- Clos de vie (début, milieu, gongs)

A. CF mimétisme des timbres. Monodie par patchwork

B. Stratification, ornementation, statisme

C. Gongs. CF virtuel, sons graves

D. Ornementation du CF 
- Java (début)

Gamelan avec orchestre symphonique.

- ME, Airs d'Espagne

Traitements monodiques et hétérophones.

- Viola Song (début)

Comme la musique indienne. Accompagnement déduit de la mélodie.

- Cantus sacri - «O quam suavis est»

Essai de chœur hétérophone.

- Plume - «Un homme paisible»

Monodrame, styles de chant pour les fonctions.

- Exemple de Ionesco : «Le futur»

Écriture vocale collée au texte. Dimension intermédiaire entre le parlé et le chanté.

- Concerto con brio (I)

Allegro de sonate?

- Merapi (III)

Hétérophonie monodique dans un cas limite.

- Ô Bali (milieu)

Forte stratification d'un CF. Ostinati.

- Piano concertant (I)

Écriture hétérophone au piano et à l'orchestre.

- Songs of the Innocence and Experience - «Ah! Sunflower»

Fausse polyphonie basée sur l'hétérophonie. Lunisson est la détente.

- Alap E Gat (CF, partie rapide)

Le CF c'est mon raga. Harmonisation d'une mélodie par elle-même. On ferme la boucle au processus initié dans Motionless Move.

- Concertino (II)

Ostinato harmonique sur des accords de quintes.

- Symphonie minute (III)

Harmonie par quintes. 